\title{
Ticagrelor and clopidogrel suppress NF-kB signaling pathway to alleviate LPS-induced dysfunction in vein endothelial cells
}

\author{
Zhuyin Jia ${ }^{1,2,3}$, Yiwei Huang ${ }^{2}$, Xiaojun $\mathrm{Ji}^{2}$, Jiaju Sun ${ }^{2}$ and Guosheng $\mathrm{Fu}^{1,3^{*}}$ (D)
}

\begin{abstract}
Background: Ticagrelor and clopidogrel, $\mathrm{P}_{2} \mathrm{Y}_{12}$ receptor antagonists, can prevent thrombotic events and are used to treat cardiovascular diseases such as acute coronary syndrome and chronic obstructive pulmonary disease, in which inflammation is involved. Moreover, NF-B is the central regulator of inflammation. Thus, we suspected that ticagrelor and clopidogrel are involved in the regulation of the NF-KB signaling pathway.

Methods: After human umbilical vein endothelial cells (HUVECs) were cultured with ticagrelor or clopidogrel and given lipopolysaccharide (LPS) and CD14, the mRNA levels of related inflammatory factors, the protein level and subcellular localization of molecules in the NF-KB signaling pathway, cell viability, apoptosis and the cell cycle, cell migration, and vascular formation were detected using quantitative polymerase chain reaction (qPCR), western blotting and immunofluorescence assay, CCK-8, flow cytometry, transwell assay, and matrigel, respectively. All data was expressed as the mean \pm S.D. The statistical significance of data was assessed by an unpaired two-tailed t-test.

Results: Ticagrelor and clopidogrel can inhibit the degradation of IKBa and phosphorylation of p65, prevent p65 from entering the nucleus, reduce the production of TNFa, IL-1, IL-8, IL-6 and IL-2, and alleviate the decrease in cell viability, cell migration and angiogenesis, the changes of cell cycle and apoptosis induced by LPS.
\end{abstract}

Conclusions: Ticagrelor and clopidogrel alleviate cellular dysfunction through suppressing NF-KB signaling pathway.

Keywords: Ticagrelor, Clopidogrel, LPS-induced dysfunction, NF-KB signaling pathway, HUVECs

\section{Background}

Clinically, ticagrelor and clopidogrel, antiplatelet agglutination agents, are commonly used in combination with percutaneous coronary intervention (PCI) for acute coronary syndrome (ACS) [1]. They cure ACS by targeting the platelet $\mathrm{P}_{2} \mathrm{Y}_{12}$ adenosine diphosphate (ADP) receptor to inhibit platelet aggregation and reduce thrombosis, and the inhibitory effect of ticagrelor on the $\mathrm{P} 2 \mathrm{Y}_{12}$ receptor is reversible, whereas inhibitory effect of clopidogrel is irreversible [2].

\footnotetext{
* Correspondence: fugs@zju.edu.cn

'Department of Cardiology, Sir Run Run Shaw Hospital, Zhejiang University School of Medicine, Hangzhou, Zhejiang, China

${ }^{3}$ Key Laboratory of Cardiovascular Intervention and Regenerative Medicine of Zhejiang Province, Hangzhou, Zhejiang, People's Republic of China Full list of author information is available at the end of the article
}

Some studies have indicated that inflammatory cytokines are involved in the initiation and progression of atherosclerosis which is one of the pathological features of ACS [3]. In addition to triggering thrombus formation at the site of atherosclerotic plaque rupture, platelets also release proinflammatory mediators and interact with other related cells, while antiplatelet therapy can reduce the levels of inflammatory cytokines [4]. Thus, inflammation plays an important role in ACS. Further research showed that NF-KB, a central regulator of inflammation, which is involved in various inflammatory diseases, is associated with susceptibility to ACS [4]. Furthermore, long-term administration of clopidogrel after severe coronary artery injury reduces inflammation via inhibition of NF-KB and activator protein 1 activation in pigs [1]. There are few reports on the mechanism of $\mathrm{P}_{2} \mathrm{Y}_{12}$ receptor antagonistmediated inhibition of inflammation. Therefore, we wanted

(c) The Author(s). 2019 Open Access This article is distributed under the terms of the Creative Commons Attribution 4.0 International License (http://creativecommons.org/licenses/by/4.0/), which permits unrestricted use, distribution, and 
to know how $\mathrm{P}_{2} \mathrm{Y}_{12}$ receptor antagonist, including ticagrelor and clopidogrel, can regulate the NF-KB signaling pathway and reduce inflammation.

In the study, we detected the mRNA levels of related inflammatory factors, the protein level and subcellular localization of molecules in the NF-KB signaling pathway, cell viability, apoptosis, the cell cycle, cell migration, and vascular formation, after treating human umbilical vein endothelial cells (HUVECs)stimulated by lipopolysaccharide (LPS) and CD14 with ticagrelor or clopidogrel.

\section{Methods}

\section{Preliminary experiment}

\section{Cell proliferation assay}

HUVECs (FuHeng Cell Center, Shanghai, China, FH0278) were incubated with ticagrelor $(0 \mu \mathrm{M}, 5 \mu \mathrm{M}, 10 \mu \mathrm{M}$, $20 \mu \mathrm{M}, 50 \mu \mathrm{M}, 100 \mu \mathrm{M})$ clopidogrel $(0 \mu \mathrm{M}, 5 \mu \mathrm{M}$, $10 \mu \mathrm{M}, 20 \mu \mathrm{M}, 50 \mu \mathrm{M}, 100 \mu \mathrm{M})$, separately, for $12 \mathrm{~h}, 24$ $\mathrm{h}$ or $48 \mathrm{~h}$. Then cell viability was determined by CCK- 8 (Biosharp, BS350B).

\section{Formal experiment Cell culture and treatment}

HUVECs were cultured in complete growth medium that was F12K containing 10\% fetal bovine serum (FBS) and 1\% Penicillin-Streptomycin Solution at $37^{\circ} \mathrm{C}$ with $5 \% \mathrm{CO}_{2}$.

HUVECs were treated with complete growth medium supplemented with DMSO (as control), ticagrelor, clopidogrel, DMSO plus LPS and CD14, ticagrelor plus LPS and CD14, or clopidogrel plus LPS and CD14, separately, for $16 \mathrm{~h}$. The concentrations of these compounds are shown in the Table 1.

\section{Cell proliferation assay}

Cells were seeded in 96 well culture plates (2000 cells/ well). After the cells were incubated with the indicated compounds for $16 \mathrm{~h}$. Finally, cell viability was tested with CCK8 reagent. We evaluated cell viability by measured the absorbance at $450 \mathrm{~nm}$.

\section{Western blot assay}

Whole cell extracts were lysed in RIPA Lysis buffer (Beyotime, P0013B) containing $1 \mathrm{mM}$ phenylmethylsulfonyl fluoride (PMSF). Then protein concentration of lysates was determined by BCA protein concentration determination kit (Beyotime, P0010). Cell lysates containing

Table 1 The concentrations of these compounds

\begin{tabular}{ll}
\hline Compounds & Concentrations \\
\hline Ticagrelor & $20 \mu \mathrm{M}$ \\
Clopidogrel & $20 \mu \mathrm{M}$ \\
LPS & $10 \mathrm{ng} / \mathrm{mL}$ \\
CD14 & $1 \mu \mathrm{g} / \mathrm{mL}$ \\
\hline
\end{tabular}

equal amount protein were resolved on a $10-12 \%$ sodium dodecyl sulfate polyacrylamide gel electrophoresis and then transferred to a PVDF membrane (Millipore, IPVH00010). After separate incubation with rabbit anti-p65 (CST, \#8242), rabbit anti-p-p65 (CST, \#3033), rabbit anti-MMP2 (proteintech, 10,373-2-AP), rabbit anti-MMP9 (proteintech, 10,375-2-AP), rabbit anti-Ecadherin (proteintech, 20,874-1-AP), rabbit anti-IKB $\alpha$ (abcam, Ab32518), rabbit anti-ICAM-1 (proteintech, 10, 831-1-AP), rabbit anti-VCAM-1 (Affinity, DF6082), rabbit anti-E-selectin (proteintech, 20,894-1-AP), rabbit antiGAPDH, mouse anti-P-selectin (proteintech, 60,322-1-Ig), mouse anti-MCP-1 (Affinity, BF0678), followed by horseradish peroxidase-conjugated secondary antibody, the membranes were visualized by ECL chemiluminescence.

\section{RNA extraction and quantitative polymerase chain reaction} ( $q P C R)$

Total RNA was extracted using TRIzol reagent (Ambion, 15,596-026), and reverse transcription was accomplished with HiScript Reverse Transcriptase (VAZYME, R101-01/02). The reverse transcription products were amplified with SYBR Green Master Mix (VAZYME, Q111-02) according to the manufacturer's instructions. The data were normalized according to the level of GAPDH expression in each individual sample. The $\mathrm{qPCR}$ primers are listed in Table 2.

\section{Immunofluorescence assay}

The cells were incubated with the indicated compounds and then fixed for $15 \mathrm{~min}$ in $4 \%$ paraformaldehyde in $1 \times$ phosphate-buffered saline (PBS) $\mathrm{pH} 7.4$. The fixed cells were permeabilized for $20 \mathrm{~min}$ with $0.5 \%$ Triton X100 in $1 \times$ PBS and then blocked in $1 \times$ PBS with $1 \%$

Table 2 The qPCR primers

\begin{tabular}{lll}
\hline Name & Primer & Sequence \\
\hline homo GAPDH & Forward & 5'- TCAAGAAGGTGGTGAAGCAGG - 3' \\
& Reverse & 5'- TCAAAGGTGGAGGAGTGGGT - 3' \\
Homo TNFa & Forward & 5'-CCCATGTTGTAGCAAACCCTC - 3' \\
& Reverse & 5'-AGAGGACCTGGGAGTAGATGA - 3' \\
& Reverse & 5'-GTGCCTCTTGCTGCTTTC - 3' \\
Homo IL-1 & Forward & 5'-CGAATCTCCGACCACCACTA - 3' \\
& Reverse & 5'-AGCCTCGTTATCCCATGTGT - 3' \\
Homo IL-6 & Forward & 5'-GGTCCAGTTGCCTTCTCCC - 3' \\
& Reverse & 5'-GTGCCTCTTTGCTGCTTTC - 3' \\
Homo IL-2 & Forward & 5'-CAACTCCTGTCTTGCATTGC-3' \\
& Reverse & 5'-TGTGAGCATCCTGGTGAGTT - 3' \\
Homo IL-8 & Forward & 5'-GACATACTCCAAACCTITCCACCCC-3' \\
& Reverse & 5'-CAAAAACTTCTCCACAACCCTCTGC -3' \\
\hline
\end{tabular}


bovine serum albumin for $30 \mathrm{~min}$. The cells were incubated with the appropriate primary rabbit anti-p65 (CST, 8242S) and then stained with Alexa Fluor Cy3labeled goat anti-rabbit immunoglobulin G (BOSTER, BA1032) and DAPI (Beyotime, C1002), separately. The subcellular localization of p65 was visualized using inverted fluorescence microscope (magnification, $\times 400$ ).

\section{Apoptosis assay}

After incubated with the indicated compounds for $16 \mathrm{~h}$, the cells were harvested and stained with APC/7-AAD apoptosis kit (SUNGENE BIOTECH, AO2001-11A-H), and then were analyzed by flow cytometry.

\section{Cell cycle assay}

After incubated with the indicated compounds for $16 \mathrm{~h}$, the cells were harvested and stained with cell cycle kit (KeyGEN BioTECH, KGA512), and then were analyzed by flow cytometry.

\section{Cell migration assay}

After treated with the indicated compounds for $16 \mathrm{~h}$, HUVECs were resuspended in serum-free F12K $(2.5 \times$ 105 cells $/ \mathrm{mL}), \quad 200 \mu \mathrm{L}$ was added to the upper chambers, and complete growth medium was added to the lower chamber. After $24 \mathrm{~h}$ incubation, cells which migrated to the lower face of the membrane were fixed with $70 \%$ ethanol solution and stained by $0.5 \%$ crystal violet. After washed by PBS for 3 times, the migrating cells were observed under a microscope and photographed (magnification, $\times 200$ ).

\section{Matrigel assay}

The cells were incubated with the indicated compounds for $16 \mathrm{~h}$, and then cultured for $6 \mathrm{~h}$ in 24-well plates coated with matrigel. The cells were imaged under an inverted microscope (Nikon, ECLIPSE Ts2) at 100 magnification and the network length and width was quantified.

\section{Statistical analyses}

All data were expressed as the mean \pm S.D. The statistical significance of data was assessed by an unpaired two-tailed t-test. A value of $p<0.05$ was used as the standard for statistical significance. All experiments were repeated 3 times or more.






\section{Results}

Ticagrelor and clopidogrel inhibit the expression of inflammatory cytokines induced by LPS

Inflammation plays an important role in the initiation and progression of atherosclerosis, indicating the involvement of inflammatory cytokines in ACS [5]. To test whether ticagrelor and clopidogrel affect the production of inflammatory cytokines, HUVECs were incubated with ticagrelor and clopidogrel at different concentrations $(0 \mu \mathrm{M}, 5 \mu \mathrm{M}, 10 \mu \mathrm{M}, 20 \mu \mathrm{M}, 50 \mu \mathrm{M}, 100 \mu \mathrm{M})$ for 12,24 and 48 h separately, without affecting cell viability (Fig. 1a). Then, HUVECs were cultured with different combinations of compounds, DMSO, ticagrelor, clopidogrel, DMSO plus LPS and CD14, ticagrelor plus LPS and CD14, and clopidogrel plus LPS and CD14, separately, for $16 \mathrm{~h}$. The results showed that ticagrelor and clopidogrel inhibited the expression of TNF $\alpha$, IL-1, IL6 , IL-8, and IL-2 induced by LPS (Fig. 1b-f). These data suggested that ticagrelor and clopidogrel inhibited the production of inflammatory cytokines.

\section{Ticagrelor and clopidogrel suppress NF-KB signaling}

Studies have shown that NF-KB is closely related to ACS, and NF-KB plays a key role in inflammation $[4,6]$. We wondered if ticagrelor and clopidogrel acted on NF$\mathrm{KB}$. The variations of molecules in the NF-KB pathway were tested after HUVECs were stimulated with LPS and given ticagrelor or clopidogrel. As a consequence, ticagrelor and clopidogrel inhibited p65 phosphorylation (Fig. 2a-b) and IKB $\alpha$ degradation (Fig. 2c-d). After HUVECs were treated with ticagrelor and clopidogrel, the amount of nuclear-translocated p65 was significantly reduced (Fig. 2e). These findings demonstrated that ticagrelor and clopidogrel inhibited the production of inflammatory factors by suppressing the NF-KB pathway.

\section{Ticagrelor and clopidogrel alleviate cellular dysfunction} through suppressing NF-KB signaling

NF-KB was shown to be involved in various biological processes, such as cell proliferation, the cell cycle, apoptosis and cell migration, by regulating the expression of various genes [3, 7-9]. Thus, we tested the cell proliferation, cell cycle, apoptosis and cell migration of HUVECs after culture with the indicated compounds (Fig. 3a-g). As shown in Fig. 3a-g, ticagrelor and clopidogrel inhibited apoptosis and the decrease in cell viability caused by LPS (Fig. 3a-c) and restored the cell migration (Fig. 3de) and the cell cycle disrupted by LPS (Fig. 3f-g). These data implied that ticagrelor and clopidogrel prevented LPS from damaging cells.

Activated NF-KB regulates the expression of a range of genes, including intercellular adhesion molecule-1 (ICAM-1), vascular cell adhesion molecule (VCAM-1), E-selectin, P-selectin, and monocyte chemoattractant protein-1 (MCP-1), which can act directly or indirectly on microvascular endothelial cells or blood cells or

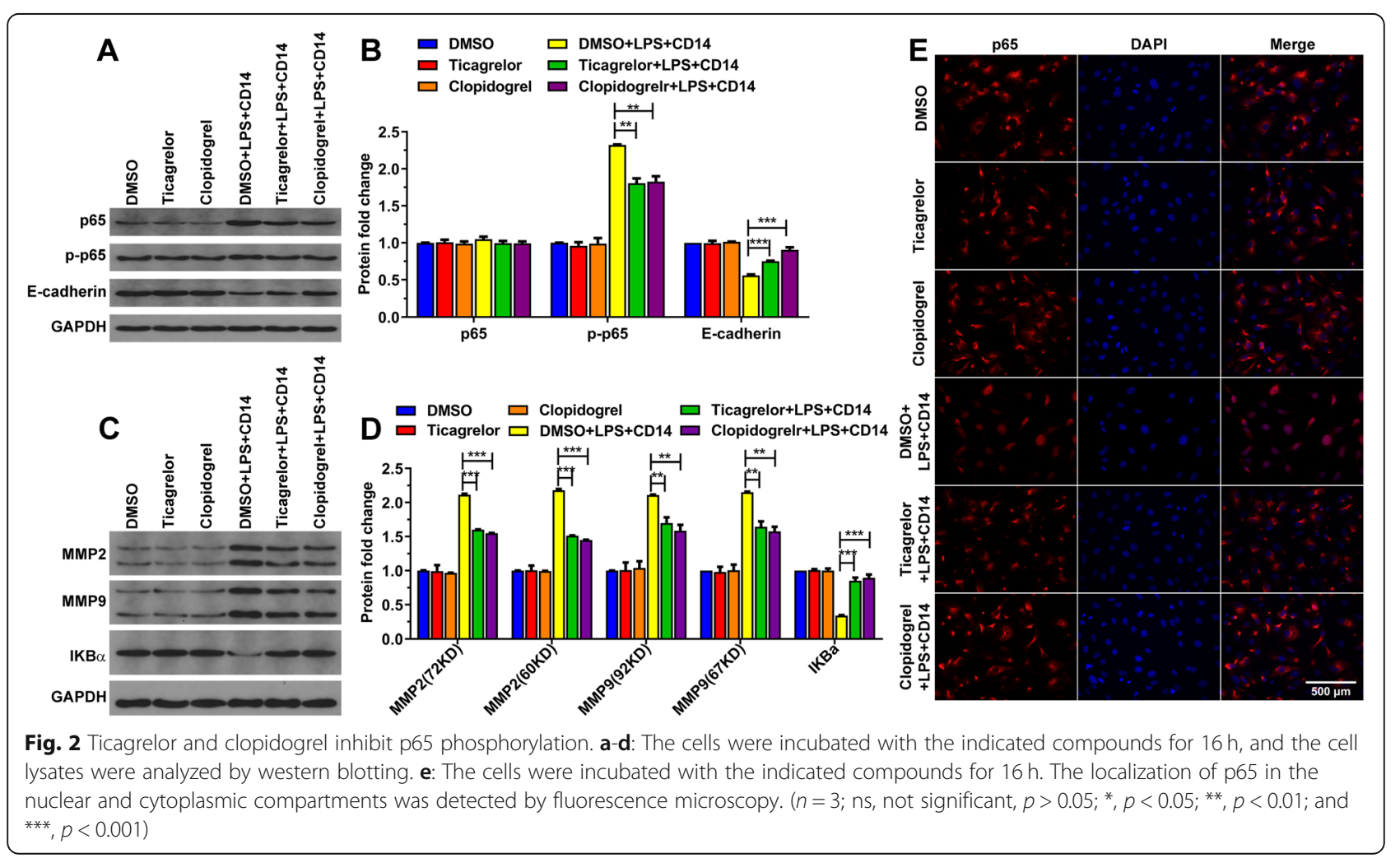




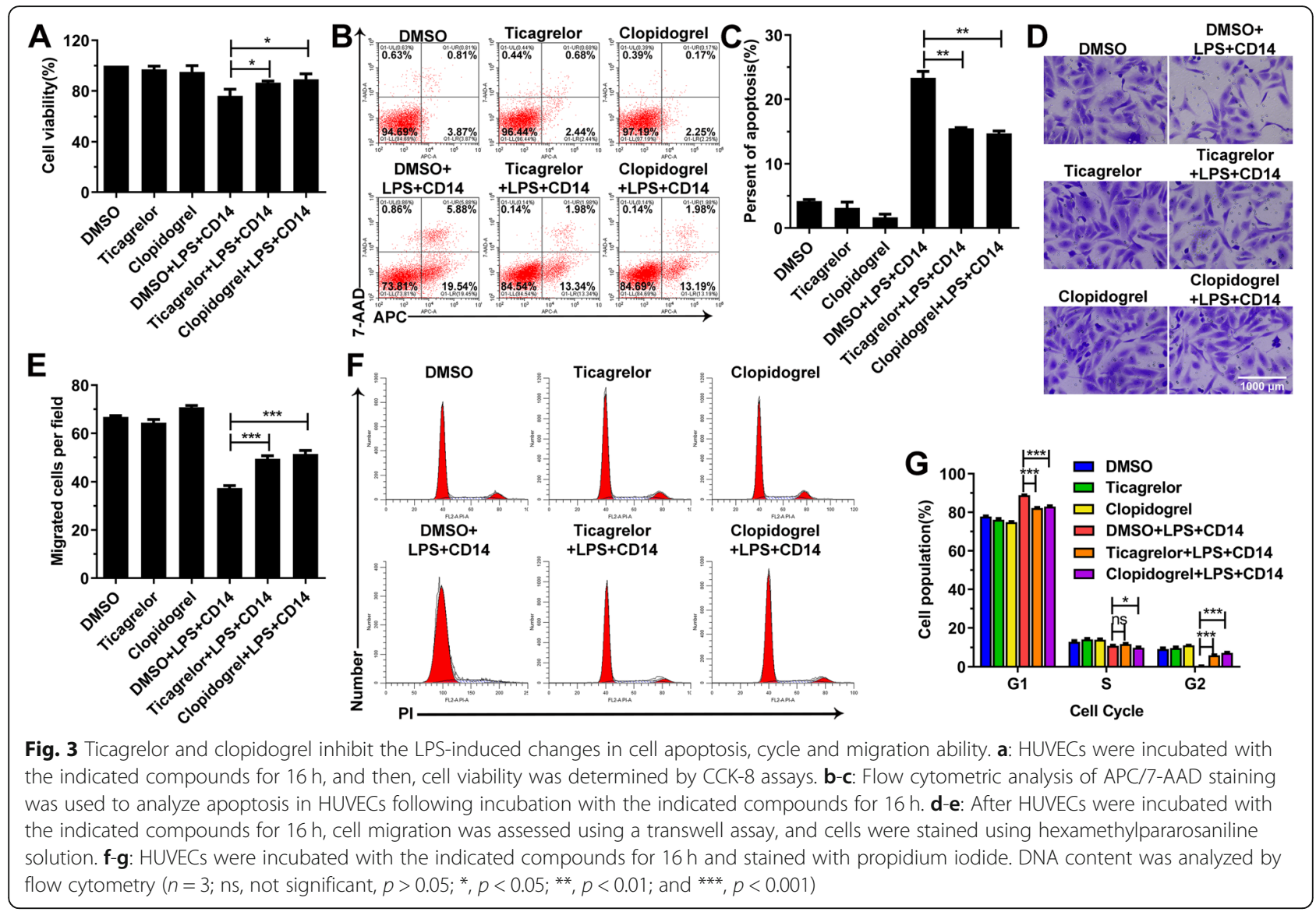

mediate their interactions, leading to microcirculation disorders $[5,10]$. Therefore, we detected their expression level and the angiogenic capacity of HUVECs treated with DMSO, ticagrelor, clopidogrel, DMSO plus LPS and CD14, ticagrelor plus LPS and CD14, and clopidogrel plus LPS and CD14. We found that ticagrelor and clopidogrel reduced the expression of ICAM-1, Eselectin, P-selectin, VCAM-1 and MCP-1 induced by LPS. (Fig. 4a-d). Furthermore, HUVECs incubated with DMSO, ticagrelor, clopidogrel, ticagrelor plus LPS and CD14, and clopidogrel plus LPS and CD14 formed complex tubular structures, whereas the total width of the tubes was significantly increased in the cells compared with those incubated with DMSO plus LPS and CD14 (Fig. 4g). Our data indicated that ticagrelor and clopidogrel restored the ability of HUVECs to generate blood vessels.

In addition, E-cadherin plays a crucial role in mediating cell adhesion and maintaining the integrity of the vascular endothelial layer. In contrast, MMP2 and MMP9 can degrade the extracellular matrix and basal membrane, damaging the vascular endothelial layer [9, $11,12]$. Hence, we also tested the expression of Ecadherin, MMP2 and MMP9. As shown in Fig. 2a-d, ticagrelor and clopidogrel increased the expression of
E-cadherin, which was reduced by LPS and restrained the expression of MMP2 and MMP9 induced by LPS. Ticagrelor and clopidogrel protected the endothelial layer from damage by NF-KB.

Overall, our findings reveal that ticagrelor and clopidogrel alleviate cellular dysfunction by suppressing NF-KB signaling.

\section{Discussion}

Currently, ticagrelor and clopidogrel are antiplatelet agents and are often used to treat ACS [13, 14]. Ticagrelor reversibly interacts with the $\mathrm{P} \mathrm{Y}_{12}$ ADP receptor, which inhibits ADP-induced platelet aggregation by blocking $\mathrm{P}_{2} \mathrm{Y}_{12}$ receptors, and does not need to be metabolically activated in the liver $[15$, 16]. Clopidogrel is a prodrug. The metabolite 2epoxy-clopidogrel is formed by the oxidation of clopidogrel and then forms active metabolites (mercaptan derivatives) through hydrolysis. Clopidogrel selectively inhibits the binding of ADP to its platelet receptor and the subsequent activation of ADPmediated glycoprotein GPIllb/llla complex, thus inhibiting platelet aggregation [4]. Clopidogrel must undergo biological transformation to inhibit platelet aggregation, but relevant active metabolites have not 


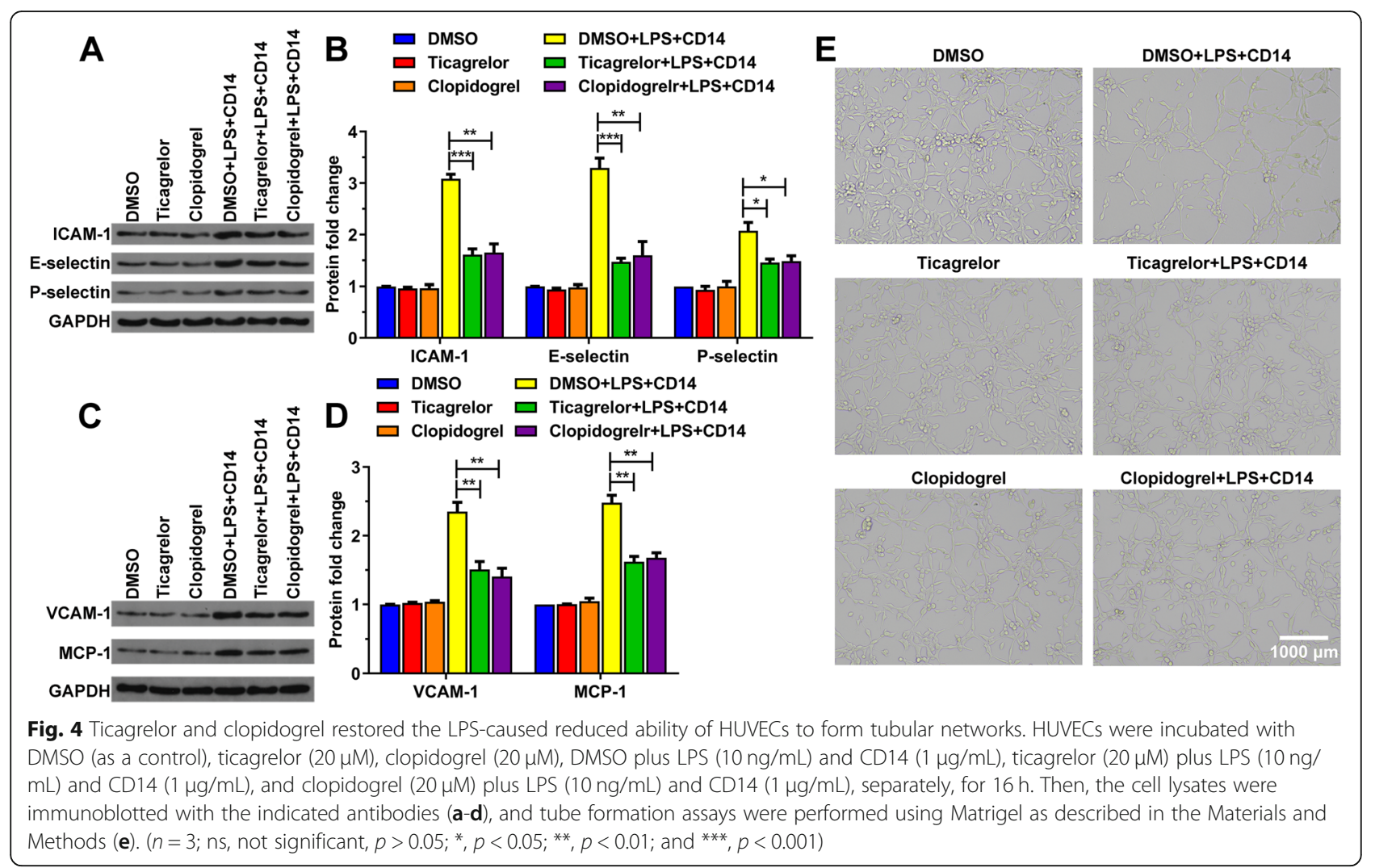

been isolated. In addition, it was reported that clopidogrel reduces inflammation via inhibition of NF-KB activation after severe coronary artery injury in pigs [1]. It can be seen that ticagrelor and clopidogrel can affect other life activities in addition to acting on the $\mathrm{P}_{2} \mathrm{Y}_{12}$ receptor leading to anticoagulation. We discovered that ticagrelor and clopidogrel protect the endothelial layer by increasing the expression of E-cadherin decreased by LPS and restraining the expression of MMP2 and MMP9 induced by LPS. Thus, ticagrelor and clopidogrel not only inhibit platelet aggregation but also protect endothelial cells. This finding is consistent with the fact that in clinical practice, ticagrelor and clopidogrel are used to prevent thrombosis and improve the nursing care of patients with ACS after PCI.

In recent years, studies have shown that NF-KB and VCAM-1 are closely related to the formation of atherosclerosis, causing deviant cell proliferation and inflammatory response, thereby affecting the stability of plaques. Moreover, NF-KB was found to be increased in ACS patients. NF-KB can transcriptionally regulate key proinflammatory cytokines, chemokines, adhesion molecules, immune recognition receptors and some enzymes in the inflammatory response and directly participate in inflammatory processes, such as inflammatory cell infusion and aggregation [5], injuring vascular endothelial cells $[9,11,12]$. Our study demonstrated that ticagrelor and clopidogrel negatively regulate the NF-KB pathway via inhibiting IKB $\alpha$ degradation and $\mathrm{p} 65$ phosphorylation, markedly reducing the amount of nuclear-translocated p65, thereby inhibiting cell apoptosis and restoring the cell cycle, cell proliferation, cell migration and formation of blood vessels, protecting cells from the damage by NF-KB. Therefore, we speculated that, in addition to inhibiting platelet aggregation, ticagrelor and clopidogrel can reduce the functional impairment of vascular endothelial cells through suppressing NF-KB signaling pathway.

Campo et al. found that ticagrelor is superior to clopidogrel in the biological effects of patients with stable coronary artery disease (SCAD) or chronic obstructive pulmonary disease (COPD) [17], while our results suggested that compared with clopidogrel, ticagrelor did not have this advantage in improving LPSinduced endothelial dysfunction. Compared with clopidogrel, there may be another more effective mechanism for ticagrelor relieving cell dysfunction to cure SCAD and COPD. We didn't have a relevant disease model and cannot directly explain the effects of ticagrelor and clopidogrel inhibiting the NF-KB signaling pathway on the treatment of disease. The role of ticagrelor and clopidogrel inhibiting the NF-KB signaling pathway in the treatment of disease requires further 
research. However, the study provided a direction for future research.

\section{Conclusions}

Ticagrelor and clopidogrel negatively regulate the NF$\mathrm{KB}$ signaling pathway via inhibiting the degradation of $\mathrm{IKB} \alpha$ and the phosphorylation and entry into the nucleus of p65 to alleviate cellular dysfunction, which provides a new theoretical basis for ticagrelor and clopidogrel curing cardiovascular diseases, such as ACS and COPD.

\section{Abbreviations}

ACS: Acute coronary syndrome; ADP: Adenosine diphosphate;

HUVECs: Human umbilical vein endothelial cells; LPS: Lipopolysaccharide; PCl: Percutaneous coronary intervention; $\mathrm{qPCR}$ : Quantitative polymerase chain reaction

\section{Acknowledgements}

Not applicable.

\section{Authors' contributions}

ZJ and GF conceived the study and designed the experiments. ZJ performed the cell proliferation assay, western blot, qRT-PCR, apoptosis, and cell cycle assay with assistance from $\mathrm{YH}$ and $\mathrm{XJ}$, and was a major contributor in writing the manuscript. YH performed the immunofluorescence assay, JS performed the migration and invasion assay. ZJ and GF wrote the manuscript. All authors discussed the results and implications and commented on the manuscript at all stages. All authors read and approved the final manuscript.

\section{Funding}

This work was supported by Wenzhou Science \& Technology Bureau (2018Y1205) and Zhejiang Provincial Department of health (General Research Program Foundation, 2016154751). These the funding bodies only provide funding and have no role in research design, data collection, analysis and interpretation, and writing manuscripts.

\section{Availability of data and materials}

The datasets generated during and/or analyzed during the current study are available from the corresponding author on reasonable request.

\section{Ethics approval and consent to participate}

Not applicable.

\section{Consent for publication}

Not applicable.

\section{Competing interests}

The authors declare that they have no competing interests.

\section{Author details}

'Department of Cardiology, Sir Run Run Shaw Hospital, Zhejiang University School of Medicine, Hangzhou, Zhejiang, China. ${ }^{2}$ Department of Cardiology, Wenzhou Central Hospital, Wenzhou, Zhejiang, China. ${ }^{3}$ Key Laboratory of Cardiovascular Intervention and Regenerative Medicine of Zhejiang Province, Hangzhou, Zhejiang, People's Republic of China.

Received: 14 August 2019 Accepted: 29 November 2019

Published online: 30 December 2019

\section{References}

1. Pels K, Schwimmbeck PL, Rosenthal P, Loddenkemper C, Dang-Heine C, Rauch U, Martens H, Schultheiss HP, Dechend R, Deiner C. Long-term clopidogrel administration following severe coronary injury reduces proliferation and inflammation via inhibition of nuclear factor-kappaB and activator protein 1 activation in pigs. Eur J Clin Invest. 2009;39(3):174-82.
2. Schneider DJ. Mechanisms potentially contributing to the reduction in mortality associated with ticagrelor therapy. J Am Coll Cardiol. 2011;57(6): $685-7$.

3. Wang S, Liu Z, Wang L, Zhang X. NF-kappaB signaling pathway, inflammation and colorectal cancer. Cell Mol Immunol. 2009;6(5):327-34.

4. Steinhubl SR, Badimon JJ, Bhatt DL, Herbert JM, Luscher TF. Clinical evidence for anti-inflammatory effects of antiplatelet therapy in patients with atherothrombotic disease. Vasc Med (London, England). 2007;12(2): 113-22.

5. Hoesel B, Schmid JA. The complexity of NF-kappaB signaling in inflammation and cancer. Mol Cancer. 2013;12(1):86.

6. Rothschild DE, McDaniel DK, Ringel-Scaia VM, Allen IC. Modulating inflammation through the negative regulation of NF-kappaB signaling. J Leukoc Biol. 2018;103(6):1131-50.

7. Baud V, Karin M. Is NF-kappaB a good target for cancer therapy? Hopes and pitfalls. Nat Rev Drug Discov. 2009;8(1):33-40.

8. Hinz M, Krappmann D, Eichten A, Heder A, Scheidereit C, Strauss M. NFkappaB function in growth control: regulation of cyclin D1 expression and G0/G1-to-S-phase transition. Mol Cell Biol. 1999;19(4):2690-8.

9. Naugler WE, Karin M. NF-kappaB and cancer-identifying targets and mechanisms. Curr Opin Genet Dev. 2008;18(1):19-26.

10. DiDonato JA, Mercurio M, Karin M. NF-kappaB and the link between inflammation and cancer. Immunol Rev. 2012;246(1):379-400.

11. Atreya I, Atreya R, Neurath MF. NF-kappaB in inflammatory bowel disease. J Intern Med. 2008;263(6):591-6.

12. Huber MA, Azoitei N, Baumann B, Grunert S, Sommer A, Pehamberger $H$, Kraut N, Beug H, Wirth T. NF-kappaB is essential for epithelial-mesenchymal transition and metastasis in a model of breast cancer progression. J Clin Invest. 2004;114(4):569-81.

13. Koyabu Y, Abe S, Sakuma M, Kanaya T, Obi S, Yoneda S, Toyoda S, Nakajima T, Inoue T. Short-term Safety and Mid-term Efficacy of Prasugrel Versus Clopidogrel in Patients Undergoing Percutaneous Coronary Intervention. Intern Med. 2019:58(16):2315-22.

14. Alomari M, Bratton H, Musmar A, Al Momani LA, Young M. Ticagrelorinduced Diarrhea in a Patient with Acute Coronary Syndrome Requiring Percutaneous Coronary Artery Intervention. Cureus. 2019;11(1):e3874.

15. Becker RC, Gurbel PA. Platelet $P 2 Y 12$ receptor antagonist pharmacokinetics and pharmacodynamics: A foundation for distinguishing mechanisms of bleeding and anticipated risk for platelet-directed therapies. Thromb Haemost. 2010;103(3):535-44.

16. Schomig A. Ticagrelor--is there need for a new player in the antiplatelettherapy field? N Engl J Med. 2009;361(11):1108-11.

17. Campo G, Vieceli Dalla Sega F, Pavasini R, Aquila G, Gallo F, Fortini F, Tonet E, Cimaglia P, Del Franco A, Pestelli G, et al. Biological effects of ticagrelor over clopidogrel in patients with stable coronary artery disease and chronic obstructive pulmonary disease. Thromb Haemost. 2017;117(6):1208-16.

\section{Publisher's Note}

Springer Nature remains neutral with regard to jurisdictional claims in published maps and institutional affiliations.
Ready to submit your research? Choose BMC and benefit from:
- fast, convenient online submission
- thorough peer review by experienced researchers in your field
- rapid publication on acceptance
- support for research data, including large and complex data types
- gold Open Access which fosters wider collaboration and increased citations
- maximum visibility for your research: over $100 \mathrm{M}$ website views per year
At $\mathrm{BMC}$, research is always in progress.
Learn more biomedcentral.com/submissions 